\title{
Agronomic and morphological performance of sorghum (sorghum bicolour l.) for the dry highlands of Kenya
}

\author{
Ouma J. P., ${ }^{*}$ Akuja T. E. ${ }^{2}$ \\ ${ }^{1}$ Department of Crops, Horticulture and Crops, Egerton University, P.O. Box 536, 20115, Egerton, Kenya. \\ 2Department of Dryland Agriculture, South Eastern University College (A Constituent College of the University of \\ Nairobi), P.O. Box 170, 90200, Kitui, Kenya \\ ${ }^{*}$ Corresponding author: jpam4_2001@yahoo.com \\ Original submitted in on $10^{\text {th }}$ January 2013. Published online at www.m.elewa.org on 30 $0^{\text {th }}$ March 2013.
}

\begin{abstract}
Objectives: The use of low yielding cultivars has been a major cause of poor sorghum production in the semi arid areas of Kenya. A study was conducted to determine the agronomic and morphological suitability of improved sorghum lines for adaptability to dry highlands of Kenya.

Methodology and Results: An experiment was set up as RCBD with 3 replicates at two sites (Nakuru and Baringo Counties) in the Rift valley Province of Kenya in March/April 2008 and 2009 to determine the plant height, flowering date, grain yield, 100-seed weight and agronomic score of 28 sorghum genotypes. Of the 28 genotypes evaluated, five lines gave significantly higher grain yield than the local check, Ikinyaruka. Mean grain yield was higher at the cooler, wetter Lanet site $\left(3587.5 \mathrm{Kg} \mathrm{ha}^{-1}\right)$ compared to the drier site, Koibatek (2298.5 Kg ha $\left.{ }^{-1}\right)$. At Koibatek, grain yield was higher in $2008\left(2298.8 \mathrm{Kg} \mathrm{ha}^{-1}\right)$ against $715.4 \mathrm{Kg}$ ha ${ }^{-1}$ for 2009. The genotypes were classified into extra early flowering and maturation (BJ 28 and IESV90015 with mean days to flowering of about 80 days; medium maturity (100-107 days to $50 \%$ flowering) and late (Koibatek local with 161 days to flower and IS 11909 with 111 days to flower).

Conclusion and application of findings: The late maturity genotypes showed potential for forage by virtue of high biomass through multiple tillering and drought recovery. The IESV series experienced less grain yield reduction compared to other lines under reduced rainfall.
\end{abstract}

Key Words: Flowering, rainfall, grain yield, agronomic score

\section{INTRODUCTION}

Sorghum is adapted to semi arid areas receiving 400 to $800 \mathrm{~mm}$ of rainfall annually by virtue of its heat and drought tolerance. With improved cultivars, appropriate water and soil management practices this amount of rainfall can support production of sorghum. Only a limited number of sorghum varieties have been developed for the dry highlands of Kenya and are mainly a few forage and dual-purpose types (Ouma et al., 1995, Ashiono et al., 2005). Seeds developed for the low altitude, high rainfall zones (western Kenya) and for the low altitude, low rainfall zones (mainly eastern Kenya) are not suitable for the low rainfall, high altitude areas (mainly Rift Valley) of Kenya. In the dry highlands, low night temperatures and occasional frost limits growth and seed set of unadapted cultivars (Arkel, 1979) making seed multiplication of un-adapted varieties unsuccessful. Previous studies have shown that sorghum cultivars adapted to high altitude, low rainfall areas 
have consistently out yielded maize grown under similar conditions (King and Mukuru, 1992) and would therefore be a suitable alternative crop during years of low rainfall. Sorghum grain yields under low input agriculture (land races, no chemical fertilizers and rain fed) range between 500 to $1000 \mathrm{~kg} / \mathrm{ha}$. The potential grain yield of improved varieties in Kenya under high altitude low rainfall conditions is about 3.8 tha ${ }^{-1}$ (King and Mukuru, 1992). In the Rift Valley province of Kenya, sorghum is mainly grown in West Pokot, Kericho, Turkana, Marakwet, Baringo and Nandi, but the grain yields are low (Anonymous, 2006). In the dry highlands, low night temperatures $<13^{\circ} \mathrm{C}$ during the flag leaf stage, can induce male sterility and reduce pollen viability (McLaren, 1997) and

\section{MATERIALS AND METHODS}

The experiment was sited at Lanet, Nakuru County; located on Latitude $0^{\circ} 30^{\prime} \mathrm{S}$ and Longitude $36^{\circ} \mathrm{E}$ at an altitude of $1920 \mathrm{~m}$ a.s.l. The mean maximum temperature during June to August period was $25.3^{\circ} \mathrm{C}$ and $28.1^{\circ} \mathrm{C}$ in 2008 and 2009 ; a minimum of $9.4^{\circ} \mathrm{C}$ and $8.7^{\circ} \mathrm{C}$ in 2008 and 2009 respectively. The soils are deep loams to sandy loam with high water holding capacity (Jaetzold et al., 2005). Sowing was done on $15^{\text {th }}$ April 2008 and harvested on $28^{\text {th }}$ October 2008 at Lanet. The rainfall received in 2008 and 2009 were $636.7 \mathrm{~mm}$ and $381.9 \mathrm{~mm}$ respectively. The second trial site was at Koibatek Agricultural training Centre, Koibatek County. ATC-Koibatek lies at latitude $1{ }^{\circ} 35^{\prime} \mathrm{S}$, and longitude $36^{\circ} 66^{\prime} \mathrm{E}$, altitude $1890 \mathrm{~m}$ a.s.l. in agroecological zone UM4, with low agricultural potential. Average annual rainfall is $767 \mathrm{~mm}$; mean annual minimum and maximum temperature are $10.9^{\circ} \mathrm{C}$ and $28.8^{\circ} \mathrm{C}$ respectively. Soils are Vitric Andosols with moderate to high soil fertility, well-drained deep sandy clay loams to sandy loam soil (Jaetzold et. al., 2005).

At Koibatek, sowing was done on $17^{\text {nd }}$ April 2008 and on $22^{\text {nd }}$ April 2009, harvesting carried out on $29^{\text {th }}$ September 2008 and on 8th September 2009 respectively. The plots were laid out as Randomised Complete Block Design with three replicates. Twenty four sorghum lines from International Crops Research Institute for the Semi arid Tropics and 4 local varieties possibly stigma receptivity (Osuna- Ortega et al., 2000) resulting in partial or complete failure of seed set. Additionally, the plants become susceptible to attacks by sorghum ergot, a nonsystemic disease of the ovaries of sorghum resulting in poor seed set and low seed quality.

The variable response of genotypes to low temperature in the dry highlands therefore necessitates evaluation of a broader range of genotypes under different sites in Kenya in order to increase the number of improved varieties adapted to these production areas. The objective was therefore to improve food security among smallscale farmers in sorghum growing areas of the dry highlands of Kenya through evaluating and selecting varieties with high and stable yields.

were evaluated, with each variety sown to four rows, $4 \mathrm{~m}$ long and $0.75 \mathrm{~m}$ apart, with intra row spacing of 0.20 $\mathrm{m}$. Blocks were separated by a $1 \mathrm{~m}$ path and plots by $0.5 \mathrm{~m}$ paths. Total plot size was $1312 \mathrm{~m} 2(0.1312 \mathrm{ha})$, but $1 / 4$ ha was prepared to grow large guard row area to limit bird damage. Fertilizer Diammonium Phosphate (18\% Nitrogen, 46\% Phosphorous) was applied at sowing, in the furrow at a rate of $36 \mathrm{~kg} \mathrm{~N}^{-1}$ and 92 $\mathrm{kg} \mathrm{P}_{2} \mathrm{O}_{5}$ ha ${ }^{-1}$. Weed control was done using 2, 4-D amine at a rate of $0.6 \mathrm{~L} / \mathrm{ha}$ at the 4 to 6 leaf stage; thereafter sorghum was manually weeded one month later. The following traits were measured to evaluate varietal behaviour: days to flowering (DF), when at least half the plants in the plot shows exposed anthers at the middle of the panicle, was recorded from date of sowing and plant height at maturity. Agronomic score was determined at maturity visually and rated from 1 to 5 , where, 1 is excellent and 5 very poor; grain yield ha ${ }^{-1}$ based on grain dry matter at harvest of ten panicles from the main stems per plot after physiological maturity, as determined by black layer formation, then oven dried at $65^{\circ} \mathrm{C} .100$-seed weight was determined after drying seed. Analysis of variance was done using the general linear model (GLM) of SAS (SAS, 2001). Mean separation was performed using Duncan's Multiple Range Test. 


\section{RESULTS AND DISCUSSION}

Plant Height: The results of the performance of sorghum lines tested at Lanet and Koibatek are presented (Table 1). There was highly significant interaction between site and genotype $(P<0.0001)$ in 2008. Genotypes BM30, Ikinyaruka and Nyundo were stable in height when moved to Koibatek. Fifteen genotypes had height reduction on being moved from Lanet to Koibatek, and 10 genotypes, i.e. E1291, MB29, BM 27, N2, BJ 28, IESV 91054LT,
IESV91069LT, IESV91071LT, IESV91015LT, and IS9203 showed height increments on being moved to Koibatek. Sorghum plants were generally taller at Lanet (mean $165.45 \mathrm{~cm}$ ) compared to Koibatek (mean 147.02 $\mathrm{cm})$. This was probably due to higher temperatures and water stress at Koibatek. At Lanet, the growing season was longer therefore sorghum was able to grow much taller, within the limits of genotype.

Table 1: Sorghum varietal performance in yield, days to flowering, plant height, 100 - seed weight and agronomic score mean of two sites in Kenya

\begin{tabular}{|c|c|c|c|c|c|}
\hline Variety & GY kg ha $^{-1}$ & DTF & $\mathrm{PH}(\mathrm{cm})$ & 100-SW & SCORE \\
\hline IS11909 & 4477.8 & $\overline{111.67}$ & 173.5 & 2.798 & 3.667 \\
\hline IS25562 & 4307.4 & 107.67 & 194.31 & 2.828 & 3.33 \\
\hline BM16 & 4187.2 & 101 & 202.64 & 2.82 & 2.5 \\
\hline S87 & 3719.5 & 104.17 & 143.19 & 2.898 & 2.83 \\
\hline BM30 & 3503.6 & 101.5 & 131.25 & 2.928 & 2.5 \\
\hline Ikinyaruka ** & 3462.4 & 91.5 & 128.38 & 3.00 & 2.83 \\
\hline E1291 & 3413.7 & 94.83 & 177.5 & 2.9633 & 2.00 \\
\hline BM18 & 3402.0 & 104.5 & 120.69 & 3.093 & 2.83 \\
\hline NYUNDO & 3236.0 & 98.6 & 120.69 & 2.880 & 3.167 \\
\hline NDAMOGA & 3230.9 & 101.17 & 141.92 & 2.890 & 3.0 \\
\hline MB29 & 3222.7 & 105.17 & 173.33 & 2.860 & 3.167 \\
\hline S79 & 3214.7 & 105 & 181.78 & 2.7217 & 3.33 \\
\hline MB39 & 3022.6 & 100.83 & 198.45 & 2.865 & 3.5 \\
\hline CYTANOMBE & 2965.3 & 105.67 & 190 & 3.032 & 3.50 \\
\hline MB30 & 2937.5 & 103.67 & 205.14 & 2.9167 & 2.33 \\
\hline URUKURAZA & 2919.4 & 103.17 & 177.14 & 2.938 & 4.167 \\
\hline IESV91054LT & 2903.9 & 103 & 119.72 & 2.728 & 2.667 \\
\hline IS9201 & 2866.5 & 104.33 & 179.28 & 2.680 & 4.33 \\
\hline IS9203 & 2729.9 & 98.83 & 153.75 & 2.870 & 2.667 \\
\hline BM27 & 2713.0 & 96.83 & 143.47 & 2.9617 & 2.833 \\
\hline ABALESHYA & 2609.6 & 103 & 135.97 & 2.8917 & 2.667 \\
\hline BM32 & 2401.8 & 103.5 & 192.67 & 3.105 & 3.00 \\
\hline IESV91069LT & 2348.4 & 96.5 & 106.53 & 3.0133 & 2.500 \\
\hline IESV91071LT & 2337.1 & 93.17 & 114.72 & 3.0133 & 2.667 \\
\hline N2 & 2091.1 & 95.75 & 144.61 & 3.0233 & 4.00 \\
\hline KOIBATEK LOCAL & 1986.2 & 161.33 & 209.86 & 2.7200 & 3.667 \\
\hline IESV90015LT & 1050.7 & 80.33 & 128.33 & 3.0400 & 4.33 \\
\hline BJ 28 & 979.1 & 81.67 & 66.81 & 2.9233 & 4.83 \\
\hline
\end{tabular}

** Local check

GY Grain yield, DTF days to $50 \%$ flowering, PH plant height SW seed weight, SCORE agronomic score

A significant interaction at $\mathrm{P}<0.046$ between year and variety for sorghum plant height was obtained. This was mainly due to the differential response of the sorghum lines to the better rainfall obtained in 2008 compared to
2009 for both trial sites (Fig 1 and 2). The influence of rainfall (Fig.1) and temperature (data not presented) was more evident at Koibatek. 


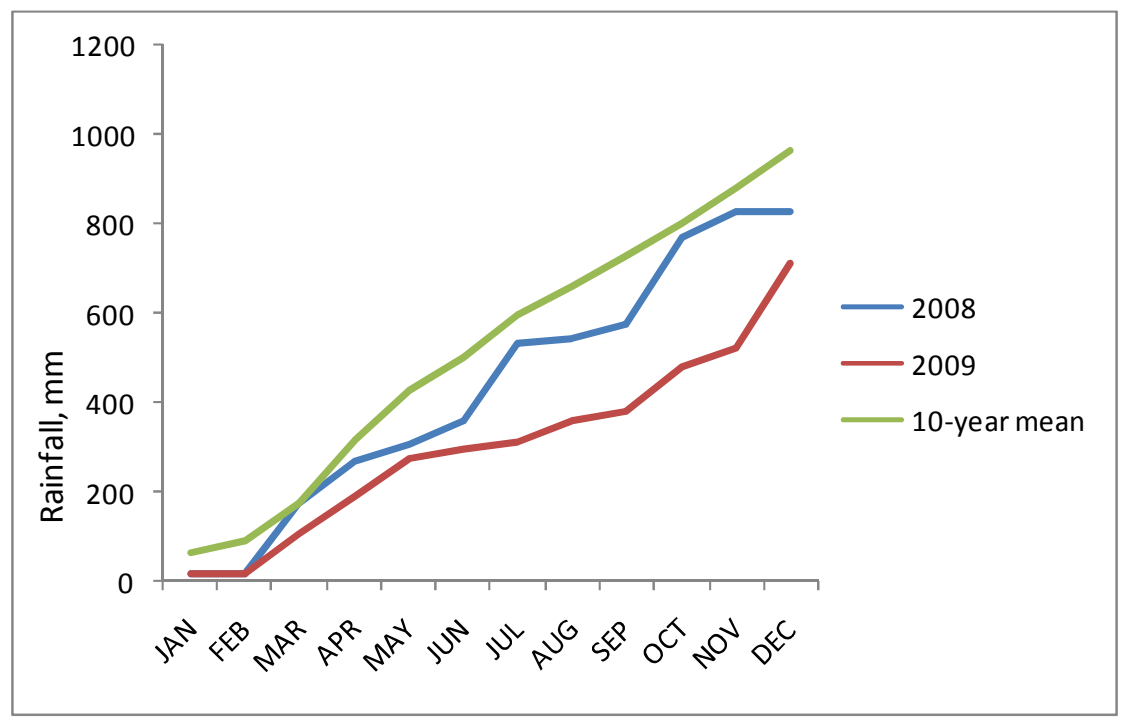

Figure 1: Cumulative rainfall at Koibatek in 2008 and 2009, during Sorghum growing period

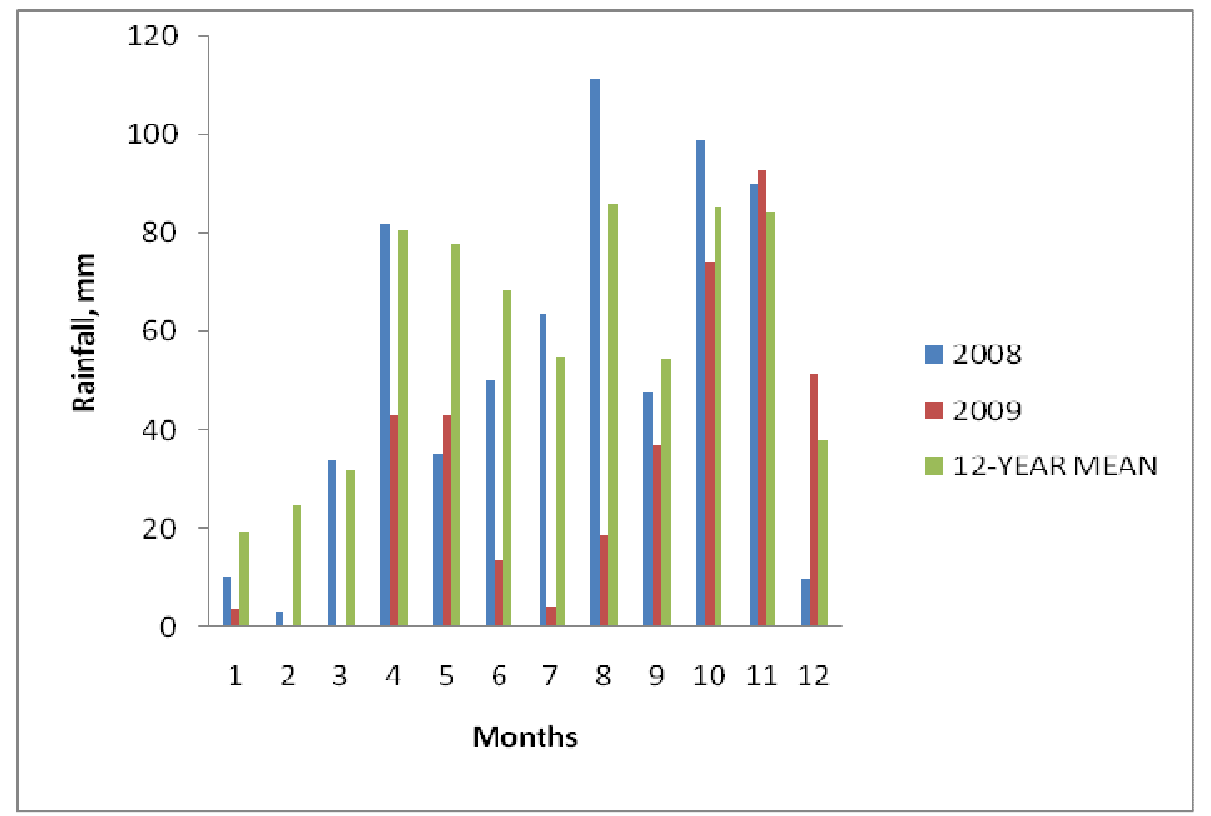

Figure 2: Distribution of rainfall at Lanet, Kenya in 2008 and 2009Days To 50\% Flowering

There was a highly significant $(P<0.0001)$ site by variety interaction for days to $50 \%$ (Table 1). The number of days to flowering ranged from 83 to $218 \mathrm{~d}$ at Lanet and from 78 to $105 \mathrm{~d}$ at Koibatek. The mean days to flowering at Lanet was 117.4 and at Koibatek 87. The varieties, which flowered earliest at Lanet, also flowered earliest at Koibatek. The rate of flowering was however accelerated at Koibatek, which is at lower altitude and warmer. A comparison of 2008 and 2009 at
Koibatek further confirmed the observation that lower rainfall contributed to earlier flowering in the sorghum lines tested. In 2008, the mean number of days to $50 \%$ flowering was 93.68 compared to 87.30 in 2009 (Table 2). This response could be due to adaptation of sorghum to water stress, to natural selection or human selection. Haussmann et al., 2006 also found that early anthesis in sorghum hybrids was the most important specific adaptation to extreme drought. 
Table 2: Sorghum varietal performance in yield, plant height and 100- seed weight at Koibatek, Kenya

\begin{tabular}{|c|c|c|c|c|c|c|c|c|c|c|}
\hline Site & \multicolumn{5}{|c|}{2008} & \multicolumn{5}{|c|}{2009} \\
\hline Genotype & $\begin{array}{l}\text { GY kg } \\
\text { ha }{ }^{-1}\end{array}$ & DTF & $\begin{array}{l}\mathrm{PH} \\
(\mathrm{cm})\end{array}$ & $\begin{array}{l}100- \\
\text { sW }\end{array}$ & SCORE & $\begin{array}{l}\text { GY kg } \\
\text { ha }-1\end{array}$ & DTF & $\mathrm{PH}$ & $\begin{array}{l}100 \\
\text { sw }\end{array}$ & SCORE \\
\hline IS11909 & 4142.11 & 94.3 & 158.67 & 2.76 & 3.3 & 0 & 108 & 113.73 & 2.61 & 4.3 \\
\hline IS25562 & 2481.22 & 90 & 149.45 & 2.65 & 2.3 & 462.37 & 93 & 173.77 & 1.65 & 4.3 \\
\hline BM16 & 3022.27 & 85.67 & 134.44 & 2.88 & 2.3 & 749.26 & 91 & 143.33 & 1.69 & 3.7 \\
\hline S87 & 2375.14 & 87.33 & 171.11 & 2.72 & 2.7 & 77.96 & 99.67 & 168.90 & 2.18 & 4.0 \\
\hline BM30 & 2851.24 & 86.3 & 143.65 & 2.76 & 2.7 & 771.0 & 95 & 152.1 & 1.68 & 2.3 \\
\hline Ikinyaruka ** & 2974.82 & 87 & 131.67 & 2.85 & 3.0 & 225.57 & 100.5 & 123.1 & 1.68 & 3.3 \\
\hline E1291 & 2573.01 & 86.33 & 143.42 & 2.8 & 2.0 & 1241.24 & 88.67 & 120.07 & 1.45 & 2.0 \\
\hline BM18 & 2637.64 & 89 & 153.17 & 2.76 & 3.0 & 776.52 & 93 & 167.63 & 2.14 & 3.3 \\
\hline NYUNDO & 2504.78 & 83.33 & 121.39 & 2.8 & 3.0 & 893.28 & 93 & 144.90 & 1.92 & 4.0 \\
\hline NDAMOGA & 2270.45 & 86 & 137.16 & 2.8 & 3.3 & 1254.17 & 90.67 & 135.23 & 1.35 & 3.0 \\
\hline MB29 & 3564.38 & 90.67 & 190 & 2.95 & 3.0 & 1457.57 & 91.67 & 178.17 & 1.91 & 2.3 \\
\hline S79 & 2494.39 & 86.33 & 141.89 & 2.57 & 3.0 & 848.61 & 93.5 & 147.47 & 1.81 & 3.3 \\
\hline MB39 & 2461.38 & 85.32 & 175.22 & 2.85 & 3.7 & 324.94 & 93 & 206.47 & 1.79 & 4.0 \\
\hline CYTANOMBE & 2246.73 & 89.67 & 147.50 & 2.74 & 3.2 & 741.98 & 91.67 & 189.17 & 1.65 & 4.0 \\
\hline MB30 & 1616.77 & 88 & 153.61 & 2.94 & 2.3 & 595.79 & 89 & 145 & 2.00 & 3.3 \\
\hline URUKURAZA & 1464.01 & 86 & 145.11 & 2.81 & 4.7 & 802.49 & 92.67 & 199.1 & 1.78 & 2.0 \\
\hline IESV91054LT & 2310 & 84.67 & 146.11 & 2.5 & 2.7 & 151.2 & 104.33 & 99.57 & 1.41 & 3.3 \\
\hline IS9201 & 1214.52 & 86.67 & 136.89 & 2.37 & 4.0 & 795.74 & 94.5 & 187.9 & 2.08 & 4.7 \\
\hline IS9203 & 1942.89 & 88 & 160.83 & 2.73 & 2.7 & 553.15 & 91.3 & 146.17 & 1.96 & 3.3 \\
\hline BM27 & 2541.51 & 85 & 158.61 & 2.73 & 2.2 & 94.47 & 90.5 & 125.90 & 2.02 & 4.0 \\
\hline ABALESHYA & 1910.38 & 86.3 & 130.28 & 2.81 & 2.0 & 812.85 & 93 & 144.80 & 1.81 & 3.0 \\
\hline BM32 & 1916.77 & 88 & 146.17 & 2.79 & 3.0 & 545.89 & 93.3 & 195.7 & 1.83 & 4.3 \\
\hline IESV91069LT & 1919.27 & 82 & 121.39 & 2.73 & 2.7 & 1143.73 & 98.33 & 109.53 & 1.53 & 1.3 \\
\hline IESV91071LT & 2068.91 & 86.67 & 141.11 & 2.93 & 3.3 & 1693.51 & 83 & 112.77 & 1.52 & 1.7 \\
\hline N2 & 1723.07 & 93.67 & 155.89 & 2.88 & 4.0 & 608.45 & 93.3 & 153.13 & 1.75 & 3.3 \\
\hline $\begin{array}{l}\text { Koibatek } \\
\text { local }\end{array}$ & 3306.38 & 104.67 & 193.89 & 2.7 & 2.3 & 0 & 110.67 & 130.93 & - & 5.0 \\
\hline IESV90015LT & 1049.21 & 77.32 & 156.67 & 2.85 & 4.3 & 979.08 & 74.33 & 124.8 & 2.24 & 3.7 \\
\hline BJ 28 & 772.82 & 80 & 111.94 & 2.59 & 4.7 & - & - & - & - & - \\
\hline MEAN & 2298.5 & 93.68 & 148.45 & 2.76 & 3.42 & 715.40 & 87.30 & 148.09 & 1.84 & 3.1 \\
\hline
\end{tabular}

GY Grain yield, DTF days to $50 \%$ flowering, PH plant height SW seed weight, SCORE agronomic score

Grain Yield: Grain yield varied significantly among varieties and between the two sites. There was no significant site $x$ variety interaction for this parameter (Table 1). Sorghum grain yield reached a mean of $3587.5 \mathrm{~kg}$ ha at Lanet compared to $2298.5 \mathrm{~kg} / \mathrm{ha}$ at Koibatek ( Table 3) The grain yield obtained at Lanet compares favourably with previously recorded sorghum yield under research management (King and Mukuru,1992; Ashiono et al., 2005) confirming the possibility of obtaining high yield at high altitude tropical areas. For all the genotypes, except Koibatek local at Lanet, there was no significant difference in seed setting of panicles, indicating that they were tolerant to low temperatures at flowering. In 2008 and 2009 the mean minimum temperature was 9.4 and $8.7^{\circ} \mathrm{C}$ during the period of June to August at Lanet.

100-Seed weight: The 100 seed weight did not differ among varieties, but the differences were highly significant between Lanet and Koibatek. The mean seed weight at Lanet was higher than at Koibatek (Table 3). This was probably due to more favourable growing conditions Lanet. 

for dry highlands of Kenya

Table 3: Mean performance of sorghum lines by site

\begin{tabular}{|c|c|c|c|c|c|}
\hline Site & GY kg ha $^{-1}$ & DTF & $\mathrm{PH}(\mathrm{cm})$ & 100- SW ( g) & SCORE \\
\hline Lanet, Nakuru County & 3587.5 & 117.4 & 165.45 & 3.069 & 3.28 \\
\hline Koibatek, Eldama Ravine County & 2298.5 & 87.4 & 147.02 & 2.757 & 3.06 \\
\hline Lsd & 245.33 & 1.87 & 9.32 & 0.286 & 0.31 \\
\hline
\end{tabular}

GY Grain yield, DTF days to $50 \%$ flowering, PH plant height SW seed weight, SCORE agronomic score

Agronomic Score: The agronomic score is a visual composite score that indicates the relative agronomic suitability of the variety for a specific purpose. It involves the simultaneous selection for grain yield and acceptable levels of other agronomic traits. It is rated from a scale of 1 to 5 , with the lower values indicating

\section{DISCUSSION}

The variation in the number of days to $50 \%$ flowering and 100-seed weight were low within each site. The number of days to flowering was significantly and positively correlated with height and yield but not 100seed weight. Under severe water stress as experienced in 2009, Days to flowering was significantly and negatively correlated with grain yield and 100 seed weight. Grain yield variation was greatest in 2009 under less rainfall confirming the conclusions that grain yield in sorghum is positively correlated with rainfall amount (Arkel, 1980). However, certain lines showed lower reduction in grain yield loss indication relative stability under limited moisture conditions. The large differences in grain yield between Lanet and Koibatek and between years at Koibatek were mainly due to difference in rainfall received during the crop growing period. This confirms the results of Arkel, 1980 within the same altitude range.

\section{CONCLUSIONS}

Reduction in rainfall caused a significant reduction in grain yield in sorghum grown at two high altitude sites in Kenya. Variation in the number of days to flowering, plant height and grain yield depended on genotype and environment. The genotypes with a combination of

\section{ACKNOWLEDGEMENTS}

The authors acknowledge Egerton University through the DVC Research and Extension for providing research funds. We are also grateful for the sorghum seeds provided by ICRISAT- Nairobi by Dr. Mary Mgonja and Mr. Erick Manyasa. The principal and field Technicians at Koibatek Agricultural Farmers Training excellent and higher values poor to very poor. It is rapid and is therefore suitable for screening out those lines under test that are poor performers. The results at both sites indicate that the varieties being evaluated were average in suitability, and no differences were discerned between the sites (Table 3).

Earlier flowering and maturing lines had relatively low grain yield. Lansac et al. (1996) found differences in seed number, and grain yield per panicle among genotypes. Earlier maturing genotypes had lower seed number and yield than medium and late- maturing genotypes, but greater seed size at low temperatures. Genetic studies have shown that phenotypic correlation between plant height and grain yield in sorghum is variable depending on the breeding lines. Mutava et al. (2011) found negative correlation between plant height and grain weight, grain numbers and yield in a study involving 300 sorghum genotypes from different races. Significant positive phenotypic correlation between plant height and days to flowering has been observed in several studies with sorghum. Such results were obtained in this study; the early lines were much shorter than late flowering lines.

medium maturity, short to medium height and stable grain yield were considered suitable for the more drought prone Koibatek site. Very early flowering and maturity genotypes were largely unsuitable due to extensive bird damage.

Centre are appreciated for providing land and technical assistance with data collection. Finally, we appreciate the contribution of the Director and Sorghum and millet Staff at KARI- Lanet for providing land and other logistic support during this experiment 


\section{REFERENCES}

Anonymous. 2006. Ministry of Agriculture Annual report, Rift valley province.

Arkel H. Van.1980. The adaptation of cold-tolerant sorghum and maize to different environments in the highlands of Kenya. Netherlands Journal of Agricultural Science, 28 (2): 78-96.

Ashiono GB, Wasike W, Ouma JP, Gatwiku SW, Gachuki PN. 2005. Residual effects of farmyard manure on stover and grain yield of cold tolerant dual-purpose sorghum (Sorghum bicolor L. Moench) in the dry highlands of Kenya. Asian J. of Agronomy 4 (4):300-303.

Haussmann B,, Schipprack IG, Geiger HH. 2006. Hybrid performance of sorghum and its relationship to morphological and physiological traits under variable drought stress in Kenya. Plant Breeding 117(3):223-229.

Jaetzold R, Schmidt H, Hornetz B, Shisanya C. 2005. $2^{\text {nd }}$ ed. Farm management handbook of Kenya Vol. II, Natural Conditions and Farm Management, Part IIB: Central Kenya. GTZ/ Ministry of Agriculture, Livestock and Marketing.

King SB, and Mukuru SZ. 1992. P.110. In: EARSAM Regional Cooperative Trials and Nurseries. In Cereal program ICRISAT Annual Report, 1992. ICRISAT, Patancheru, A.P. India.

Lansac AR, Sullivan CY, Johnson BE.1996. Accumulation of free proline in Sorghum (Sorghum bicolor) pollen. Can.J. Bot. 74: 4045.

Mutava RN, Prasad PVV, Tuinistra MR, Kofoid KD,Yu. J. 2011. Characterization of sorghum genotypes for traits related to drought tolerance. Field Crops Research 123 (1):1018.

http://dx.doi.org/10.1016/i.fcr.2011.04.006, $\underline{\text { Ho }}$ $w$ to Cite or Link Using DOI

McLaren NW, and Flett BC.1998. Use of weather variables to quantify sorghum ergot potential in South Africa. Plant Disease 82(10): 26-29.

Osuna-Ortega J, Mendoza-Onofre LE, GonzalezHenandez VA, Castillo- Gonzalez F, Mendoza-Castillo $M$, Willaiams-Alanis $H$. 2000. Potential of Cold tolerant germplasm the adaptation and adaptability of sorghum in Mexico: I. High Valleys. Agroencia 34: 561572.
Ouma JP, Irungu KRG, Gaithuma MN, Maina PM. 1995. Highland forage sorghum in Kenya: What Prospects? p. 192 - 195. In: S.Z. Mukuru and S.B. King (Eds.) Proc. Eighth EARSAM Regional Workshop on Sorghum and Millets, 30 Oct - 5 Nov 1992 Wad Medani, Sudan

SAS Institute. 2001. SAS User's guide, release 8.1: SAS Institute, Cary, NC, USA. 